\title{
KAJIAN KERENTANAN PENGHIDUPAN TERHADAP FENOMENA ROB DI BAGIAN WILAYAH KOTA (BWK) III KOTA SEMARANG
}

\author{
Oleh: \\ Rahma Hayati \\ Jurusan Geografi, Fakultas Ilmu Sosial, Universitas Negeri Semarang \\ rahma_to@yahoo.co.id
}

\begin{abstract}
Abstrak
Kajian tentang kerentanan merupakan hal penting dalam kajian penghidupan berkelanjutan. Studi mengenai kerentanan menjadi hal penting dalam berbagai langkah pembangunan berkaitan dengan masalah bencana, kemiskinan, perencanaan perkotaan maupun perdesaan, dan masalah pembangunan lainnya. Beberapa hal pokok yang dapat dipakai sebagai kerangka untuk studi kerentanan, yaitu: 1) sumber kerentanan, 2) area dan kelompok penduduk yang terpapar bencana, 3) kemampuan bertahan dan kemampuan pulih. Sumber kerentanan yang mengancam penghidupan di BWK II Kota Semarang adalah bencana genangan rob. Area yang terpapar bencana rob di BWK III Kota Semarang semakin meluas, yaitu 34 kelurahan pada tahun 2000 dan 35 kelurahan pada tahun 2005. Penduduk di BWK III Kota Semarang secara pribadi dan bersama telah melakukan tindakan bertahan terhadap bencana genangan rob dengan meninggikan lantai rumah, lahan pekarangan dan jalan umum. Pemerintah kota secara kelembagaan telah melaksanakan proyek-proyek fisik untuk menghindarkan wilayah dari bencana genangan rob dengan meninggikan jalan Kapasitas wilayah yang berupa system drainase dan pintu-pintu pompa air seyogyanya dimanfaatkan dengan baik, sehingga kemampuan wilayah untuk terhindar dari bencana genangan rob semakin baik. Tindakan untuk menghindar dari bencana genangan rob secara parsial-lokal-individual memiliki potensi konflik yang besar.
\end{abstract}

Kata kunci: kerentanan, terpapar, kemampuan bertahan, kemampuan pulih.

\section{A STUDY ON THE LIVELIHOOD VULNERABILITY TOWARD THE PHENOMENA OF ROB IN THE CITY REGION (BWK) III SEMARANG}

\begin{abstract}
The study on vulnerability is important in the study of sustainable livelihoods. Also, this study is important in various steps of development with regard to the problem of disaster, poverty, urban and rural planning, and other development issues. Some main points that can be used as a framework for the study of vulnerability include: 1) a source of vulnerability, 2) areas and group of people hit by the disasters, 3) the ability to survive and recover. The sources of vulnerability that threaten the livelihoods in BWK III Semarang is Rob flood. The areas which are hit by this disaster in BWK III Semarang has increasingly widespread i.e. 34 villages in 2000 and 35 villages in 2005. The residents in BWK III Semarang have performed an action to survive against this disaster by raising the height of the floor, yard and public roads. The local government has implemented physical projects to prevent this disaster from happening by improving the capacity of the region such as improving the quality of road drainage systems and water pumps doors. Therefore, the region can stand from the disaster better. The partial - local individual action to avoid this disaster has a great potential for conflict.
\end{abstract}


Keywords: vulnerability, hit by disaster, ability to survive, ability to recover.

\section{Pendahuluan}

Sebagai negara kepulauan, wilayah pesisir Indonesia memiliki nilai strategis dengan berbagai keunggulan komparatif dan kompetitif yang dimilikinya sehingga berpotensi menjadi penggerak pengembangan wilayah nasional. Bahkan secara historis menunjukan bahwa wilayah pesisir ini telah berfungsi sebagai pusat kegiatan masyarakat karena berbagai keunggulan fisik dan geografis yang dimilikinya. Semakin meningkatnya jumlah penduduk dan intesitas pembangunan ekonomi, maka tekanan lingkungan terhadap wilayah pesisir terutama berupa konflik pemanfaatan ruang dan sumberdaya alam serta pencemaran, juga akan semakin kompleks dan membengkak. Apalagi jika dikaitkan dengan kemungkinan munculnya dampak pemanasan global (global warming) terhadap kawasan pesisir, khususnya peningkatan permukaan laut (sea-level rise) (Dahuri et al, 2001), maka tantangan pengelolaan wilayah pesisir di masa depan tidak mungkin dapat diatasi hanya dengan pendekatan sektoral dan hanya mementingkan keuntungan jangka pendek.

Pada proses pengembangan Kota Semarang banyak dijumpai kendala yang disebabkan oleh kondisi topografinya yang cukup bervariasi. Topografi wilayah Kota Semarang terbagi menjadi dua bagian yaitu wilayah Semarang bawah yang merupakan daerah dataran rendah berdekatan dengan pantai di bagian utara dan wilayah Semarang atas yang merupakan daerah perbukitan dengan ketinggian antara 90 - 200 meter di atas permukaan air laut (DPL) di bagian selatan kota.

Pengembangan Kota Semarang dibagi ke dalam BWK (Bagian Wilayah Kota) untuk lebih meningkatkan efisiensi dan arah wilayah pengembangannya. BWK III Kota Semarang yang meliputi Kecamatan Semarang Barat dan Kecamatan Semarang Utara memiliki peran sebagai kawasan pengembangan dengan fungsi utama sebagai Kawasan Permukiman, Kawasan Pusat Kota dan Pusat Transportasi Kota yang ditunjang dengan berbagai fungsi pendukung yaitu Fungsi Pelayanan Umum. Hal ini berdampak pada perkembangan BWK III yang begitu pesat, sehingga mendesak dibangunnya sarana dan prasarana untuk menunjang berbagai macam aktifitas manusia seperti pembangunan kawasan permukiman, kawasan industri, kawasan perdagangan serta bangunan sarana dan prasarana perkotaan.

Perubahan pola penggunaan lahan di Kota Semarang telah memberi dampak kurang baik, antara lain telah mengakibatkan terjadinya bencana banjir, khususnya banjir karena pasang air laut atau biasa disebut rob. Bencana banjir atau genangan rob selalu menimbulkan kerusakan sarana dan prasarana perkotaan sehingga dapat menghambat aktifitas kehidupan manusia. Rob akibat terjadinya pasang air laut yang melanda Kota Semarang sudah ada sejak lama. Dari tahun ke tahun daerah yang terkena rob semakin meluas. Rob menggenangi permukiman dan jalan yang ada khususnya di Bagian Wilayah Kota (BWK) III Kota Semarang. Kondisi ini cukup mengganggu dan membuat penduduk tidak nyaman. Berbagai upaya telah dilakukan oleh penduduk secara swadaya maupun oleh Pemerintah Kota Semarang agar tempat tinggalnya atau daerahnya dapat terhindar dari genangan rob. Namun demikian kemampuan itu sangat terbatas, sehingga terdapat sekelompok penduduk maupun daerah-daerah tertentu yang penghidupannya terancam oleh bahaya genangan rob. Dengan kata lain terdapat kerentanan penghidupan karena ancaman bahaya genangan rob.

Kajian tentang kerentanan penghidupan merupakan bagian yang tak terpisahkan dari kajian penghidupan berkelanjutan (Sustainable Development). Chambers (1992) memberikan pengertian tentang penghidupan adalah sebagai berikut: 
A livelihood comprises the capabilities, assets (including both material and social resources) and activities required for a means of living. A livelihood is sustainable when it can cope with and recover from stresses and schocks and maintain or enhance its capabilities and assets both now and in the future while not undermining the natural resource base.

Pengertian tersebut menjelaskan bahwa penghidupan terdiri dari kemampuan, aset (termasuk material dan sumber daya sosial) dan kegiatan yang dibutuhkan sebagai sarana hidup. Penghidupan yang berkelanjutan adalah ketika bisa mengatasi dan pulih dari tekanan dan goncangan dan mempertahankan atau meningkatkan kemampuan dan aset baik sekarang dan di masa yang akan datang sementara tidak merusak sumber daya alam.

Selanjutnya pengertian penghidupan oleh DFID (1999) merupakan adaptasi dari Chambers (1992), mengemukaan bahwa dalam pendekatan penghidupan berkelanjutan terdapat beberapa unsur yang harus dipahami yaitu: konteks kerentanan, aset-aset penghidupan, struktur dan proses yang berubah, strategi penghidupan dan hasil-hasil penghidupan, seperti dalam skema Gambar 1. Dalam konteks tersebut masyarakat hidup dan demi kelangsungan hidup dan penghidupannya bertumpu pada aset-aset penghidupan yang beragam.

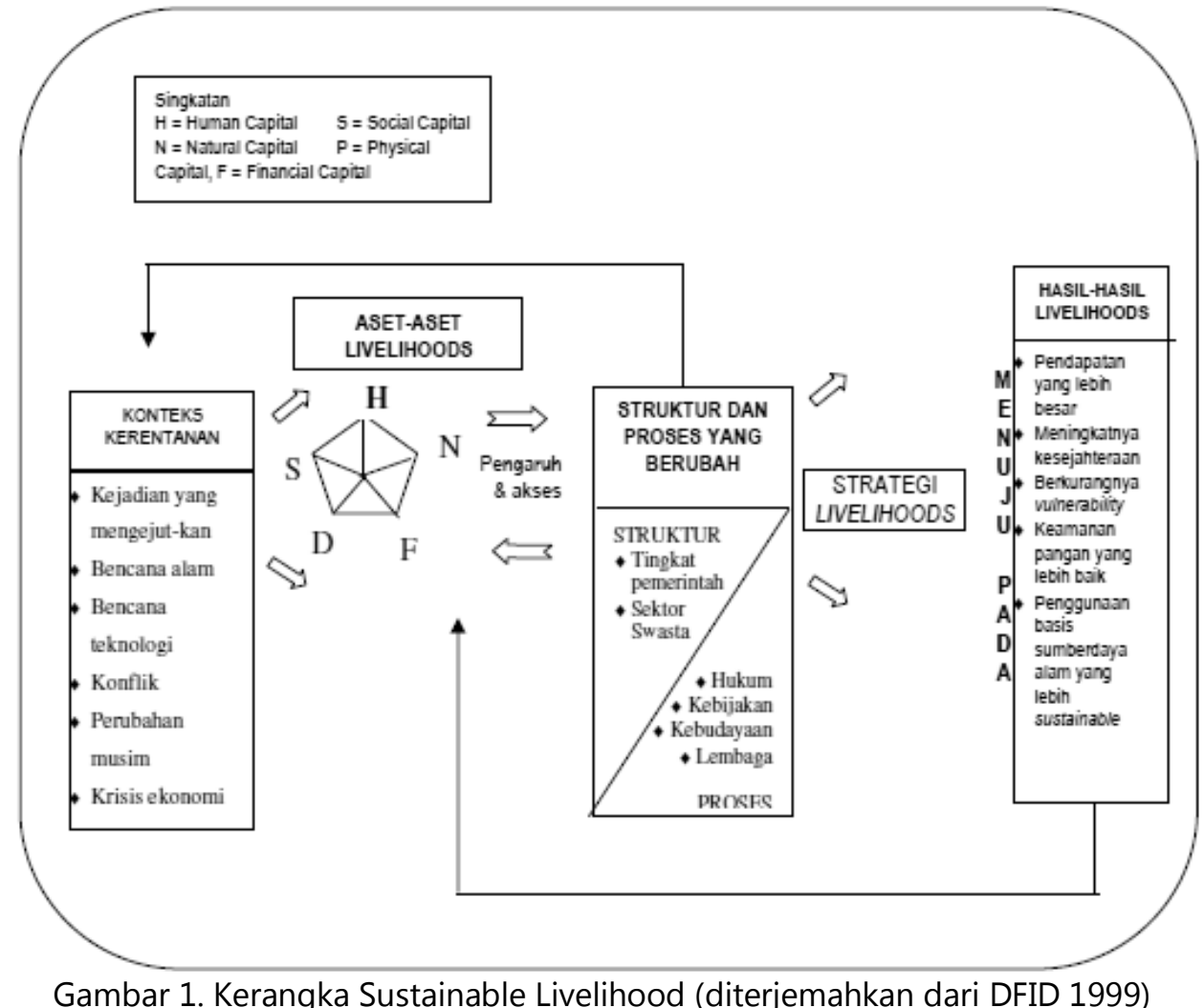

Melihat beberapa pengertian di atas, maka kajian tentang kerentanan merupakan hal penting dalam kajian penghidupan berkelanjutan. Kajian tentang kerentanan dipopulerkan oleh Robert Chambers (1983) dalam Wisner (2009). Dalam kajian tersebut disebutkan bahwa kerentanan merupakan satu dari lima elemen yang saling terkait satu dengan lainnya, yang kemudian disebut 'ratchet effect' atau 'depriviation trap', yaitu suatu kondisi kemiskinan perdesaan secara menyeluruh yang sulit untuk dipisah- 
pisahkan. Elemen lain adalah ketidakberdayaan secara politik, kelemahan secara fisik, isolasi lokasi dan pendapatan yang sangat rendah.

Kajian mengenai kerentanan sudah diterapkan pada 25 (dua puluh lima) tahun terakhir ini. Pada perkembangannya paling tidak terdapat 5 (lima) bidang kajian yang menggunakan kerentanan (Wisner, 2009), yaitu penelitian tentang bahaya dan kebencanaan, pendampingan bantuan kemanusian, kesehatan masyarakat, perubahan iklim dan studi pembangunan. Masing-masing kajian memiliki cara yang berbeda dalam memberi batasan tentang kerentanan, tetapi tetap menuju pada pemahaman mengenai ancaman yang tidak dapat ditempatkan secara tepat dalam kajian tersendiri mengenai iklim, pembangunan, konflik ataupun kesehatan.

Sebuah pendekatan untuk menilai kerentanan telah dikembangkan pada tahun 1980-an dan 1990-an (Wisner, 2009). Pendekatan ini untuk menetapkan dan menganalisis kerentanan dan kapasitas yang mencoba mengkaitkan penghidupan, lokasi dan kondisi ekologis dengan akses terhadap politik, pengetahuan lokal dan relasi sosial. Pendekatan ini dibangun di atas prinsip-prinsip penelitian partisipatif (Participatory Action Research/PAR). Dalam pendekatan ini penduduk dapat menentukan sendiri kerentanan mereka dengan menggunakan alat-alat yang sederhana, sehingga pendekatan ini sering disebut penilaian sendiri atau self assessment. Dengan demikian self assessment tidak hanya fokus pada bencana dan kerentanan tapi juga pada kapasitas. Pada pendekatan ini pengetahuan yang berasal dari luar mungkin baik untuk dibawa masuk dan bercampur dengan pengetahuan lokal. Sebagai pengetahuan, ini ditambahkan, bukan sebagai pengganti yang asli yang sudah sangat dipahami penduduk.

Clark (1998) melakukan penelitian tentang kerentanan yang berkaitan dengan perubahan iklim. Pada penelitian ini dilakukan penilaian kerentanan terhadap badai ekstrim pada komunitas penduduk pantai di Revere, MA, Amerika Serikat,. Dalam penelitian tersebut dijelaskan bahwa perubahan iklim mempengaruhi frekuensi, intensitas dan distribusi geografis dari badai. Penelitian tersebut memahami secara bersama kerentanan fisik dan sosial dalam menghadapi bencana badai dan berbagai akibatnya.

Sage (2002) melakukan penelitian tentang kerentanan penghidupan di Somalia, karena kebijakan pembangunan yang bersifat "predator" dan penghabisan sumberdaya alam, serta iklim yg sering ekstrim. Hasil penelitian menunjukkan bahwa kerentanan yang ada di Somalia pada umumnya disebabkan oleh multistress dan multishock, antara lain sumberdaya alam yang miskin, keterbatasan metode tradisional dalam produksi pertanian dan peternakan, dan dampak dari praktek ekonomi dan politik non-liberal.

Ford (2004) melakukan penelitian untuk menilai kerentanan pada komunitas "Canadian Arctic" karena ancaman perubahan iklim. Penelitian tersebut mengembangkan konseptual kerentanan, yang menyatakan bahwa kerentanan merupakan fungsi dari paparan dari bencana, tekanan iklim dan kapasitas adaptasi untuk mengatasi stres tersebut.

Shahbaz (2008) melakukan penelitian di barat laut Pakistan. Penelitian tersebut mengkaji kerentanan penghidupan masyarakat yang tinggal di daerah dataran tinggi dan tandus terhadap perubahan global dan globalisasi. Kerentanan di daerah penelitian tersebut disebabkan oleh banyak hal yaitu karena penyakit, pelayanan kesehatan yang jelek, degradasi sumberdaya alam, goncangan harga, kekurangan pangan, dan kesempatan kerja yang sifatnya musiman. Dalam penelitian tersebut dikembangkan konsep tentang resiko dan kerentanan untuk mitigasi sindrom, yang meliputi skala dan distribusi resiko dan kerentanan, kelompok atau individu yang paling rentan, dan dukungan struktural baik secara potensial maupun kenyataan saat ini.

Fraser (2011) melakukan kajian dari beberapa penelitian tentang kerentanan untuk mengetahui bagaimana konseptualisasi kerentanan terhadap perubahan iklim dalam 
gabungan sistem sosial-ekologi dan mendapatkan tantangan metodologis untuk antisipasi trend dalam kerentanan karena dinamika lingkungan. Dari kajian yang telah dilakukan, diidentifikasi terdapat empat langkah metodologis dan selanjutnya diikuti dengan studi kasus untuk lebih menggali elemen-elemen yang berbeda. Empat langkah tersebut adalah (1) menggunakan pendapat dan publikasi para pakar, (2) memilih model konseptual pada system penghidupan yang focus pada tiga dimensi kerentanan, (3) mengarahkan penggunaan analisis kerentanan kualitatif dengan tiga bagian yang harus ada yaitu agroekologikal, asset rumah tangga dan faktor-faktor kelembagaan, serta (4) mengarahkan penggunaan analisis kerentanan secara kuantitatif yang secara numerik membantu dalam penetapan hipotesis untuk menduga kerentanan yang akan datang.

Beberapa studi tentang kerentanan tersebut di atas telah membawa studi mengenai kerentanan menjadi hal penting dalam berbagai langkah pembangunan berkaitan dengan masalah bencana, kemiskinan, perencanaan perkotaan maupun perdesaan, dan masalah pembangunan lainnya. Dari beberapa studi tersebut terdapat beberapa hal pokok yang sama yang dapat dipakai sebagai kerangka untuk studi kerentanan, yaitu: 1) sumber kerentanan, 2) area dan kelompok penduduk yang terpapar bencana, 3) kemampuan bertahan dan kemampuan pulih. Pada kesempatan ini akan dibahas mengenai tiga hal tersebut berkaitan dengan fenomena rob di BWK III Kota Semarang.

\section{Tujuan Penelitian}

Penelitian ini bertujuan untuk mengkaji fenomena rob di BWK III Kota Semarang khususnya mengkaji tentang kerentanan penduduk, yang meliputi: 1) sumber kerentanan, 2) area dan kelompok penduduk yang terpapar bencana rob, 3) kemampuan bertahan dan kemampuan pulih dari bencana rob.

\section{Metode Penelitian}

Penelitian dilaksanakan di seluruh wilayah Bagian Wilayah Kota (BWK) III Kota Semarang, Provinsi Jawa Tengah yang terdiri dari Kecamatan Semarang Barat dan Kecamatan Semarang Utara. Penelitian dilakukan dengan mengumpulkan data sekunder dan data primer yang bersifat kualitatif. Data sekunder yang dikumpulkan berkaitan dengan kuantitas bencana rob antar tahun. Data primer yang dikumpulkan berkaitan dengan informasi langsung dari penduduk dan instansi mengenai tindakan-tindakan yang telah dilakukan untuk bisa bertahan terhadap bencana rob.

\section{Hasil dan Pembahasan \\ Ancaman Bahaya Genangan Rob}

Rob atau pasang air laut yang sering disebut dengan genangan air laut, merupakan genangan yang disebabkan oleh pasang air laut, umumnya terjadi pada daerah dekat pantai. Daerah yang terkena pasang air laut umumnya mempunyai elevasi permukaan tanah $\pm 1,5$ meter. Kejadian rob (pasang air laut) terjadi hampir tiap hari pada saat air laut pasang dengan ketinggian yang bervariasi (DPU Kota Semarang, 1995: dalam Kusumaningtyas, 2002 ).

Proses terjadinya genangan rob disebabkan oleh berbagai faktor yang dapat dikelompokkan menjadi beberapa faktor antara lain; pertama karena faktor alami seperti intesitas curah hujan yang tinggi dan karakteristik daerah yang memang lebih rendah dari permukaan pasang air laut dan bisa juga disebabkan oleh adanya gaya gravitasi terhadap benda lain contohnya gravitasi bulan. Faktor yang kedua adalah bukan alami atau ada campur tangan (kepentingan) manusia seperti pengambilan air bawah tanah yang berlebihan dengan cara sumur bor, pengurangan daerah resapan yang berlebihan, 
reklamasi pantai, tambak-tambak dan rawa-rawa, serta meninggikan bangunan yang belum mengindahkan drainasi yang baik (Banoor, 2009).

Menurut Liesnoor (2004) genangan karena pasang air laut atau rob memberikan dampak negatif yang menimbulkan kerusakan lingkungan, kehidupan berusaha, dan aktifitas kemasyarakatan lainnya. Dampak genangan rob menurut tingkat kerugiannya dapat dibedakan menjadi kerugian langsung, kerugian tidak langsung, kerugian tak terwujud.

\section{Wilayah Terkena Rob di BWK III Kota Semarang}

Wilayah terkena rob dalam hal ini sampai tergenang rob di BWK III Kota Semarang memiliki variasi persebaran. Di wilayah Kecamatan Semarang Utara pada tahun 2004 terdapat 12 titik persebaran rob dengan genangan tertinggi mencapai $75 \mathrm{~cm}$ yang berlokasi di Kelurahan Bulu Lor di Jln. Gendomono. Pada titik terendahnya di Kelurahan Dadapsari, Jln. Layur dengan tinggi genangannya $20 \mathrm{~cm}$. Sedangkan rata-rata tinggi genangan dari keseluruhan wilayah persebaran rob adalah $40 \mathrm{~cm}$.

Pada tahun 2008 wilayah yang terkena rob di Kecamatan Semarang Utara mengalami perluasan di berbagai titik lokasi di seluruh lingkungan kelurahan. Kecamatan Semarang Utara terkena rob dengan tinggi genangan antara $10-60 \mathrm{~cm}$, dengan rata-rata tinggi genangan rob mencapai $35 \mathrm{~cm}$. Kelurahan Panggung Lor pada tahun 2008 sudah tidak tergenang rob, dan pada tahun 2010, persebaran rob di Kecamatan Semarang Utara telah mengalami penurunan di berbagai titik lokasi di seluruh kelurahan yang ada di Kecamatan Semarang Utara.

Kawasan genangan rob di Kota Semarang dari tahun ke tahun secara umum semakin meluas. Hal ini dapat dilihat dari luas genangan rob yang semakin bertambah pada tahun 2000 sampai dengan tahun 2005. Pada tahun 2000 jumlah wilayah yang tergenang rob seluas $2.202,53 \mathrm{Ha}$, sedangkan pada tahun 2005 wilayah yang tergenang seluas 2.497,22 $\mathrm{Ha}$, atau dapat dikatakan luas genangan bertambah menjadi kawasan rob baru sebesar 294,69 Ha. Wilayah yang sudah tidak tergenang rob yaitu Kelurahan Krobokan Kecamatan Semarang Barat. Sedangkan wilayah yang tergenang rob bertambah di Kecamatan Semarang Tengah pada Kelurahan Kranggan, Kelurahan Sekayu, Kelurahan Kembang Sari dan Kecamatan Genuk pada Kelurahan Terboyo Wetan dan Kelurahan Trimulyo. Dilihat secara administrative, juga terdapat kenaikan jumlah kelurahan yang terkena genangan rob. Pada tahun 2000 terdapat 34 kelurahan terkena genangan rob. Jumlah tersebut menjadi 35 kelurahan pada tahun 2005. Dengan demikian secara kualitas maupun kuantitas, area terkena genangan rob di BWK III Kota Semarang terus meningkat. Secara spasial, area genangan rob di BWK III Kota Semarang dapat dilihat pada peta 1 dan 2 . 


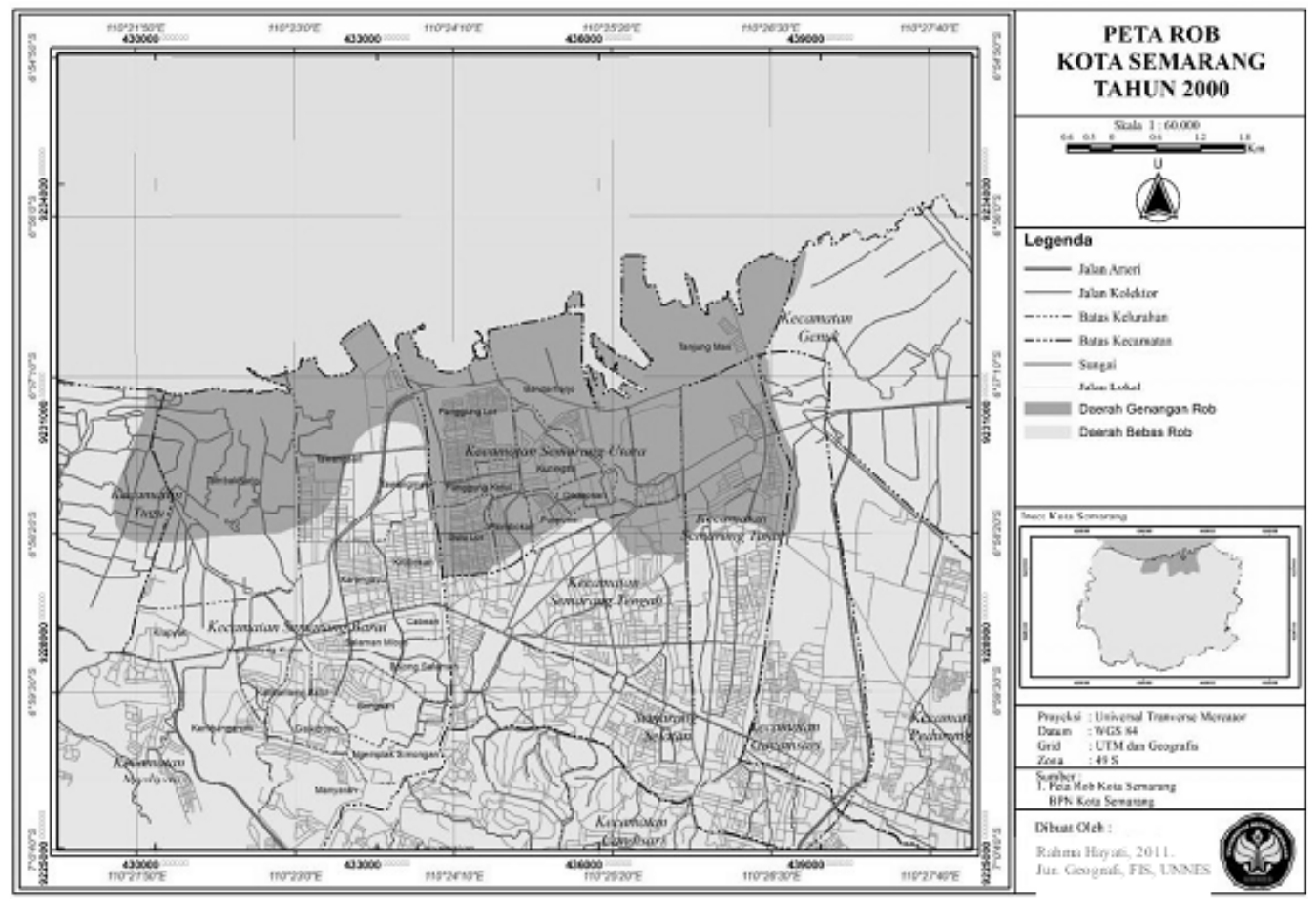

Peta 1. Area Genangan Rob BWK III Kota Semarang Tahun 2000

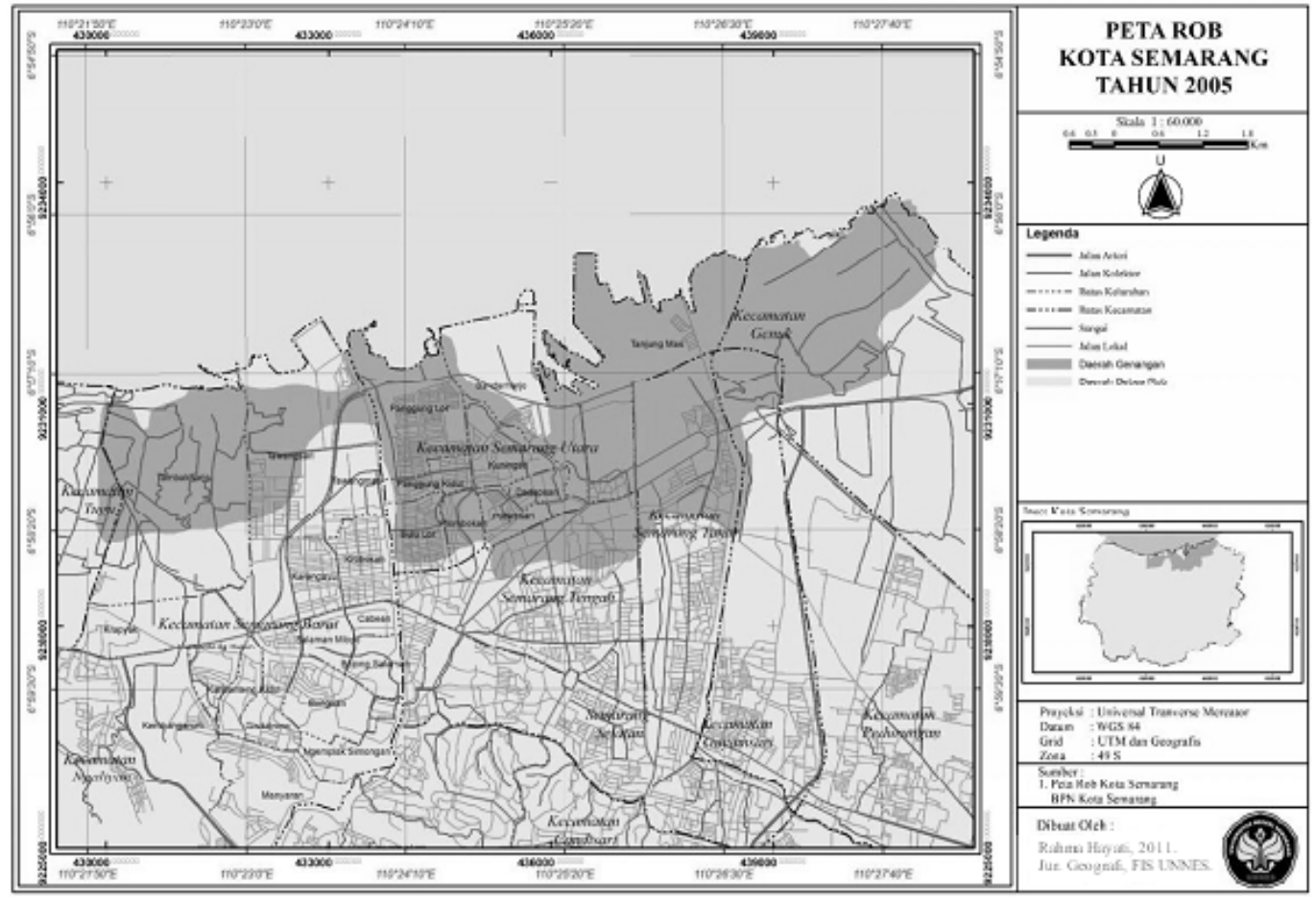

Peta 2. Area Genangan Rob BWK III Kota Semarang Tahun 2005

\section{Kemampuan Bertahan dan Pulih dari Bencana Genangan Rob}

Bencana membuat orang berpikir untuk tetap tinggal di tempat tersebut dengan konsekuensi selalu dalam posisi terancam, atau pergi meninggalkan tempat tersebut untuk menghindar dari ancaman. Keputusan untuk tetap melanjutkan kehidupan di lokasi bencana mengharuskan orang untuk melakukan sesuatu agar terhindar dari bencana yang mungkin akan muncul lagi, atau terhindar dari dampak buruk bencana yang datang. 
Kasus bencana genangan rob di BWK III Kota Semarang telah membuat penduduk secara perorangan, penduduk sebagai warga masyarakat dan pemerintah kota melakukan berbagai tindakan untuk tetap bertahan di wilayah genangan rob.

Salah satu tindakan untuk menghindar dari bencana genangan rob secara pribadi telah dilakukan oleh banyak warga. Salah satunya adalah Ny Warsito yang bertahuntahun pernah tinggal di Jl Cumi-cumi Kelurahan Bandarharjo yang merupakan salah satu titik genangan rob di Kota Semarang. Usaha yang pernah dilakukan agar terhindar dari genangan rob adalah dengan menaikkan lantai rumah. Setiap tiga tahun sekali Ny Warsito harus meninggikan lantai rumahnya hanya sekadar menghindar dari air. Ny Warsito sudah tiga kali meninggikan lantai bangunan rumahnya. Pertama ditinggikan $75 \mathrm{~cm}$, kemudian $50 \mathrm{~cm}$, dan terakhir juga $50 \mathrm{~cm}$. Ternyata genangan rob terus mengancam kehidupan Ny Warsito, sehingga sejak enam tahun yang lalu Ny Warsito memutuskan untuk meninggalkan $\mathrm{Jl}$ Cumi-cumi dan pindah ke salah satu rumah susun di Bandarharjo, di lantai dua. Itu merupakan contoh bagaimana seseorang bertahan dan akhirnya menghindar dari paparan bencana genangan rob.

Secara swadaya masyarakat dan melalui proyek-proyek pembangunan fisik di Kecamatan Semarang Utara, telah dilakukan berbagai kegiatan/tindakan untuk menghindar dari bencana genangan rob. Tindakan tersebut antara lain dengan menguruk jalan, sehingga beberapa penggal jalan yang sebelumnya selalu terkena genangan rob kemudian bisa terhindar dari rob. Tindakan tersebut nampak pada data tahun 2010 yang menunjukkan bahwa persebaran genangan rob di Kecamatan Semarang Utara telah mengalami penurunan di berbagai titik lokasi di seluruh kelurahan yang ada di Kecamatan Semarang Utara.

Tindakan menguruk lahan dan jalan seperti di atas ternyata memiliki potensi konflik yang luas. Ketika salah satu daerah yang tergenang rob meninggikan wilayahnya, maka sifat dasar air akan selalu mencari daerah yang lebih rendah, dan itu akan menggenang ke wilayah lainnya yang lebih rendah dari wilayah tetangganya, sehingga antar daerah akan selalu berlomba-lomba untuk meninggikan wilayahnya agar terhindar dari genangan rob.

Dari gambaran-gambaran konflik yang ada, yang juga memprihatinkan adalah kemungkinan adanya konflik horizontal antar golongan masyarakat di lingkungan tersebut. Fenomena pembangunan-pembangunan sektoral secara lokal-individual akan menimbulkan degradasi lingkungan di wilayah lokal yang lain. Pembangunan sektoral lokal -individual inilah yang kemudian memacu masyarakat untuk terus melakukanya demi mencapai kondisi lingkuanganya yang dirasa ideal dengan mengesampingkan kondisi di wilayah lainnya. Lama kelamaan hal ini akan menimbulkan konflik sosial yang terbuka, terlebih lagi jika menyangkut mengenai strata sosial dan ekonomi.

\section{Kapasitas Wilayah (Sistem Drainase)}

Membicarakan kerentanan penghidupan, selain membahas ancaman bencana, area dan penduduk terpapar, serta kemampuan bertahan dan pulihnya, maka pembahasan mengenai kapasitas yang dimiliki wilayah dalam menghadapi dan menghindar dari bencana juga penting. Dalam hal bencana genangan rob di BWK III Kota Semarang, maka kapasitas wilayah yang akan dibahas adalah tentang drainase wilayah. Sistem drainase wilayah sangat mendukung kemampuan wilayah tersebut untuk menghindar dari bencana genangan rob.

Dilihat dari sistem drainase, di BWK III terdapat enam (6) sub system sungai. Dua sub system sungai besar yaitu Sungai Banjir Kanal Barat dan Kali Semarang yang berhulu di Sungai Ungaran dan berfungsi sebagai saluran pembuangan (drainase dan limbah) utama Kota Semarang (saluran primer), dan empat sub system sungai kecil, 
yaitu Sungai Buntu, Tambakharjo, Siladak, Semanggu, Banger yang memiliki fungsi sebagai saluran sekunder untuk pembuangan (drainase dan limbah rumah tangga), dan untuk saluran tersier berada pada saluran di tiap-tiap lingkungan pemukiman.

Sub Sistem Kali Banjir Kanal Barat Banjir Kanal Barat merupakan terusan dari Kali Garang yang bersumber di Gunung Ungaran. Kali Garang memiliki dua buah anak sungai, yaitu: Kali Kripik dan Kali Kreo yang mempunyai panjang masing-masing 12 $\mathrm{km}$ dan $10 \mathrm{~km}$. Pada jalur Kali Garang terdapat Bendung Simongan yang terletak 5,3 $\mathrm{km}$ dari muara sungai. Luas DAS Banjir Kanal Barat ini adalah 20004,5 ha dan terletak di 2 (dua) kab/kota yaitu Kota Semarang 10232,65 ha Dan Kabupaten Semarang 9771,85 ha. Pendangkalan saluran oleh karena sedimentasi menjadi masalah utama pada sub sistem ini. Disepanjang Kali Banjir Kanal Barat, terdapat dua stasiun pompa yaitu di Bulu dan di Basudewo. Kedua stasiun pompa ini membuang air dari sub sistem Bulu ke Kali Banjir Kanal Barat.

Sub Sistem Kali Bulu Sub sistem Kali Bulu mempunyai 3 outlet ke Banjir Kanal Barat yang dilengkapi dengan pintu. Saluran baru juga telah dibangun sepanjang 1,4 $\mathrm{km}$ disepanjang J. Kokrosono, saluran ini terhubung dengan saluran di Jl. Palgunadi. Luas DAS sub sistem ini adalah 93,57 ha. Permasalahan utama yang terjadi di Kali Bulu ini adalah sedimentasi dan sampah. Menurut data yang didapatkan dari subdin perairan Pemerintah Kota Semarang, di sub sistem Kali Bulu terdapat 2 stasiun pompa yaitu di Buludrain dan Basudewo. Stasiun pompa di Bulu melayani daerah seluas 302 ha, yang meliputi : a. Jl. Hasanudin b. Jl. Brotojoyo c. Panggung Lor d. Panggung Kidul e. Bulu Lor f. Pindrikan Aliran dari keenam daerah tersebut di pompa ke Kali Banjir Kanal Barat dengan kapasitas pompa screw pump 2 @1.400 Lt/det dan pompa axial 2@100. Sedangkan stasiun pompa Basudewo membuang air dari daerah Bulustalan dan Lemah Gempal ke Banjir Kanal Barat. Pompa di Basudewo ini menggunakan pompa axial dengan kapasitas $50 \mathrm{Lt} /$ det.

Sub Sistem Kali Asin Kali Asin bermuara ke Kali Semarang yang mempunyai daerah tangkapan 281,35 ha. Di Kali Asin ini terdapat 3 pompa. Permasalahan utama yang terjadi pada sub sistem ini adalah sedimentasi yang tinggi, bahkan di Kelurahan Purwosari tinggi sedimentasi mencapai 1,5 m. Talud Kali Asin di Kelurahan Kuningan terjadi kebocoran dan perlu perbaikan secepatnya.

Sub Sistem Kali Semarang Kali Semarang mempunyai daerah tangkapan seluas 576,28 ha. Kali Semarang ini mempunyai 2 saluran, yaitu Kali Asin dan Drainase Simpang Lima. Untuk mengurangi genangan banjir di Simpang Lima dan beban Kali Semarang, Saluran Simpang Lima di outletkan ke Banjir Kanal Timur melewati Saluran Kartini. Permasalahan yang terjadi pada sub sistem ini adalah sedimentasi yang tinggi.

Sub Sistem Kali Bandarharjo Sub Sistem Bandarharjo terdiri dari Bandarharjo Barat yang terdapat di Kelurahan Tanjungmas dan Bandarharjo Timur yang terdapat di Kelurahan Tanjungmas dan Kelurahan Bandarharjo. Luas daerah alirannya adalah 302,07 ha. Sebagian besar sub sistem ini terletak di elevasi yang rendah sehingga jika air laut pasang tinggi maka akan terjadi genangan rob. Selain genangan rob, pada sub sistem ini terjadi sedimentasi yang tinggi.

Saluran drainase tersier BWK III berada pada tiap-tiap lingkungan permukiman. Secara umum kondisi jaringan drainase tersier yang ada di BWK III sebagian besar masih menggunakan jaringan yang berupa saluran-saluran tanah. Hanya beberapa saluran di tepi jalan yang sudah berupa saluran dan beton. Kondisi tersebut mengakibatkan banjir atau genangan yang ada di BWK III saat ini sudah hampir mencakup semua kelurahan yang ada khususnya untuk Kecamatan Semarang Utara.

Kapasitas wilayah yang berupa saluran drainase baik system primer, sekunder maupun tersier yang ada di wilayah ini merupakan pendukung yang bagus bagi BWK III 
untuk mengelola wilayahnya agar terhindar dari bencana genangan rob. Masalah-masalah yang berkaitan dengan system drainase yaitu sedimentasi dan kualitas saluran, apabila diselesaikan dengan baik akan sangat membantu wilayah tersebut terhindar dari bencana genangan rob.

\section{Penutup}

Sumber kerentanan yang mengancam penghidupan di BWK II Kota Semarang adalah bencana genangan rob. Area yang terpapar bencana rob di BWK III Kota Semarang semakin meluas, yaitu 34 kelurahan pada tahun 2000 dan 35 kelurahan pada tahun 2005. Penduduk di BWK III Kota Semarang secara pribadi dan bersama telah melakukan tindakan bertahan terhadap bencana genangan rob dengan meninggikan lantai rumah, lahan pekarangan dan jalan umum. Pemerintah kota secara kelembagaan telah melaksanakan proyek-proyek fisik untuk menghindarkan wilayah dari bencana genangan rob dengan meninggikan jalan Kapasitas wilayah yang berupa system drainase dan pintupintu pompa air seyogyanya dijaga dan dimanfaatkan dengan baik, sehingga kemampuan wilayah untuk terhindar dari bencana genangan rob semakin baik. Tindakan untuk menghindar dari bencana genangan rob secara parsial-lokal-individual memiliki potensi konflik yang besar.

\section{Daftar Pustaka}

Baiquni, Muhammad. 2006. Pengelolaan Sumberdaya Perdesaan Dan Strategi Penghidupan Rumahtangga Di Provinsi Daerah Istimewa Yogyakarta Pada Masa Krisis (1998-2003). Disertasi. Yogyakarta: Universitas Gadjah Mada,.

Bappeda. 2004. Rencana Tata Ruang Wilayah Kota Semarang Tahun 2000 -2010. Bappeda Kota Semarang.

Bappeda. 2008. Rencana Detail Tata Ruang Kota, Bagian Wilayah Kota III Tahun 20102030. Bappeda Kota Semarang.

Chambers, R. \& Conway, G. R. 1992. Sustainable Rural Livelihoods: Practical Concepts for the 21st Century University of Sussex, Working Paper No. 296, Brighton: IDS.

Chambers, R. 1989. Vulnerability, Coping and Policy. IDS. Bulletin 20(2): 1-7

Clark, George E., Susanne C. Moser, Samuel J. Ratick, Kirstin Dow, William B. Meyer, Srinivas Emani, Weigen Jin, Jeanne X. Kasperson, Roger E. Kasperson And Harry E. Schwarz., 1998, Assessing the Vulnerability of Coastal Communities to Extreme Storms: The Case Of Revere,MA., USA. Journal: Mitigation and Adaptation Strategies for Global Change3.C 1998 Kluwer Academic Publishers. Printed in the Netherlands

Creswell, John W. 2010. Research Design Pendekatan Kualitatid, Kuantitatif dan Mixed. Yogyakarta: Pustaka Pelajar

Dahuri, et al. 2001. Pengelolaan Sumberdaya Wilayah Pesisir dan Lautan Secara Terpadu. Jakarta. PT. Pradnya Paramita.

DFID. 1999. Sustainable Livelihoods Guidance Sheets. London: DFID.

Fraser Evan D. G., Andrew J. Dougill, Klaus Hubacek, Claire H. Quinn, Jan Sendzimir and Mette Termansen. 2011. Assessing Vulnerability to Climate Change in Dryland Livelihood Systems: Conceptual Challenges and Interdisciplinary Solutions. Ecology and Society, Volume 16, Number 3.

Kusumaningtyas, Wiwik. 2002. Dampak Rob Terhadap Permukiman Penduduk Di Kecamatan Semarang Utara (Studi Kasus Di Kelurahan Bandarharjo). Skripsi. Semarang FIS. UNNES. 
Liesnoor, Dewi. 2004. Genangan Pasang Air Laut (Rob) Pada Kawasan Pantai Kota Semarang. Makalah disajikan dalam Seminar Proceeding Coastal Ecosystem For Social Prosperty. Yogyakarta. Fakultas Geografi UGM.

Wisner, B. 2009. Vulnerability ( a part of International Encyclopedia of Human Geography, Volume Six). The Netherland: Elsevier. 
Kajian Kerentanan Penghidupan Terhadap Fenomena Rob di Bagian Wilayah Kota (BWK) III Kota Semarang 